Historical Issues in Sleep Medicine

\title{
Sante De Sanctis (1862-1935), a forerunner of the 20th century research on sleep and dreaming
}

\author{
Renato Foschi, Giovanni Pietro Lombardo, Giorgia Morgese * \\ Archive of the History of Psychology, History of Psychology Laboratory, Department of Dynamic and Clinical Psychology, Sapienza University of Rome, Italy
}

\section{A R T I C L E I N F O}

\section{Article history:}

Received 8 May 2014

Received in revised form 8 July 2014

Accepted 1 August 2014

Available online 13 November 2014

\section{Keywords:}

History of the dream psycho- and

neurophysiology

Dreaming and sleeping phases

REM and Non REM sleep

Activation-synthesis hypothesis

\begin{abstract}
A B S T R A C T
This article aims to reconstruct the elements of continuity and/or discontinuity in Sante De Sanctis' (18621935) contributions in the scientific understanding of sleep and dreaming as compared to the scientific research of his time. An Italian psychologist and psychiatrist, De Sanctis, in his work conducted between the 19th and 20th centuries, has framed the study of dreams using multi-methodology. In addition, De Sanctis experimentally established the correspondence between the deep and desynchronization phases of sleep with respect to dreaming. In this context, De Sanctis' subjects described the periodicity of sleep and consciousness, influencing the explanations of the themes that modern sleep research has, after decades, systematically studied. We demonstrate that De Sanctis' work has been underestimated, and in our opinion, deserves to be reconsidered as a source of the psychophysiological explanation of dreams and sleep. Finally, we present a graphical representation of De Sanctis' psycho- and neurophysiological model of dreaming.
\end{abstract}

(c) 2014 Elsevier B.V. All rights reserved.

\section{Introduction}

This article aims to highlight the aspects that bind contemporary scientific research with the studies on sleep and dreaming led by the Italian psychologist and psychiatrist Sante De Sanctis (18621935 ), between the end of the 19th century and the beginning of the 20th century (Fig. 1).

Sante De Sanctis is considered to be one of the "pillars" of Italian psychology. He played a decisive role in forming the foundation of psychology in Italy during the late 19th and early 20th centuries. His work was extraordinarily fruitful with varying interests: his contributions ranged from general and experimental psychology to applied psychology in judicial, criminal, educational, psychotechnical, and psycho-pathological areas [1].

The scientific study of dreams was probably the area that, more than any other, made the Italian psychologist internationally known. According to Pigman, Sante De Sanctis was the only scholar of the 20th century to contradict the "myth" of the original psychoanalytic foundation of the psychological study of dreams [2]. In 1901, James M. Baldwin (1861-1934) and George Frederick Stout (18601944) recognized this role, proclaiming that the work done by De Sanctis in 1899 was the best work on dreams in their famous

\footnotetext{
* Corresponding author. Archive of the History of Psychology, History of Psychology Laboratory, Department of Dynamic and Clinical Psychology, Sapienza University of Rome, Italy. Tel.: +390649917628; fax: +390649917628.

E-mail address: giorgia.morgese@uniroma1.it (G. Morgese).
}

Dictionary of philosophy and psychology in the section entitled "Dream" [3].

In the experimental layout, the author's works seem to have anticipated the explanation of some of the aspects of dreaming that are still considered central aspects of current dream research. Despite this, contemporary scholars of dreams do not seem to mention the work of De Sanctis; he was only cited for some of his observations regarding the dreams of animals [4,5]. Moreover, De Sanctis is not even mentioned in the more recent literature regarding the history of sleep and dream research [6].

In this regard, we refer to the reconstruction made by recent historiographies. These historiographies demonstrate that, starting from the second half of the 19th century, even before Sigmund Freud's (1856-1939) psychology of dreams, some scholars used a systematic and empirical approach to study dreams $[2,7,8]$.

Even so, between the 19th and 20th centuries, the objective study of sleep and dreams had developed in a pioneering manner involving different methods. In this period, the idea that mental pathology could be a sort of waking dream was prominent. Psychoanalysis later expanded upon this idea with a method that seemed to be the most promising for studying dreams. First, the initial attempts to study dreams by "experiments" were made by manipulating the sleeper and trying to understand the symbols "hidden" in the dreams (Maury, Scherner, Calkins) or studying dreams through diaries at night (Hervey de Saint-Denys, Spitta, Tarde). On the basis of physiology, stimulations and registrations described the first depth-of-sleep curves and respiratory rhythm (Marey, Mosso, Luciani, Kohlschütter). Moreover, at the beginning of the 20th century, some researchers believed that sleep and dreams were caused by specific toxins that 


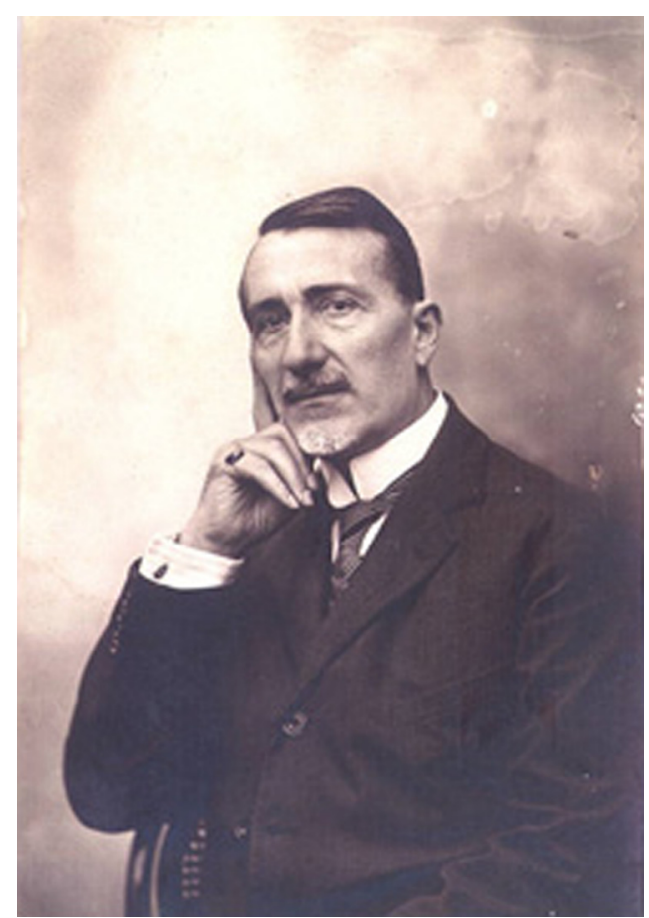

Fig. 1. Sante De Sanctis (1862-1935). The photograph is reprinted with permission of De Sanctis' family.

hit the central nervous system at night (Vaschide, Pieron). At the same time, the first questionnaires to collect and catalog the contents of dreams were developed (Heerwagen, Calkins) $[6,7,9,10]$.

De Sanctis' considerations on sleep and dreams were based upon his in-depth knowledge of the most updated international literature. On the other hand, the German neurologist and psychiatrist Hans Berger (1873-1941) [11] devised - in the twenties - the electroencephalogram which became the most widely used methodology for studying sleep and dreams in the laboratory. Berger, while known to De Sanctis, was only mentioned in studies regarding vasomotor changes in the brain during sleep [12].

De Sanctis' theoretical model of the dream was thus affected by insights and tools that were limited by his time. In fact, in the early 20th century, the progress of scientific knowledge of experimental techniques used to study dreams were characterized by a psychophysiological approach, without a clear neurophysiological precision that only developed following the discovery of the electroencephalogram. Therefore, using this point of view, this article intends to describe and deepen the themes, the models and the interpretive insights originally advanced by De Sanctis, linking them to the further development of modern research on sleep and dreams.

\section{De Sanctis and scientific research on sleep and dreams in the 20th century}

Since the early studies of the late 19th century, research on sleep and dreams unraveled throughout the course of De Sanctis' scientific career [9]. In 1899, I sogni: studi clinici e psicologici di un alienista (Dreams: Psychological and clinical studies of an alienist) [13], the best-known book by De Sanctis on the psychology of the dream, was published. Among others mentioned by Sigmund Freud (18561939), I sogni included a beneficial integration of clinical methods, consisting of the use of specifically designed questionnaires that were applied to a differential study of dreams. In fact, the Italian scholar, using a multi-methodology (which he called the "integral method"), developed a real dream psychology from a psycho-physiological point of view according to an evolutionary perspective beginning with his monograph, I sogni [13], and continuing in his work Le condizioni fisiologiche del sogno (The physiological conditions of the dream) (1920) [12] and finally, Nuovi contributi alla psicofisiologia del sogno (New contributions to the psychophysiology of dreams) (1933) [14].

In particular, as discussed by Lombardo and Foschi [10], some turning points of De Sanctis' research can be illustrated by the following:

- The original use of specialized tools for psycho-physiological analysis, such as the esthesiometer and pneumograph, used to study sleep and the oneiric conscience.

- The existence of specific sleep stages to which the occurrence of the dream phenomenon corresponds.

- The definition of the prominent role of the activation of the brainstem as a neurophysiological correlate in the dream process.

\subsection{The depth-of-sleep curve and the dream curve}

Sante De Sanctis was influenced by the research on depth-ofsleep curves by Kohlschütter, Michelson and Kraepelin, who would awaken the sleepers using auditory stimulation $[9,15]$. De Sanctis improved this method by using the esthesiometer by Hermann Adolf Griesbach (1854-1941), professor of Hygiene at the University of Giessen, who suggested that mental fatigue could be measured through changes in the tactile perception of the skin. This tool was used to achieve the stimulation of a single functional point upon awakening (if provoked), but not produce any painful sensation in the subject.

In a major international article, Investigations concerning the depth of sleep, written in collaboration with Umberto Neyroz (18771927) at the beginning of the 20th century, a survey of normal and abnormal (primarily epileptic) participants was presented, in which the first signs of the origins of De Sanctis' dream model were clear. In fact, in this earlier article published with Neyroz in 1902, a study regarding the physiological sleep conditions that were required in order to understand dream activity, according to De Sanctis, was included [16].

The graph in Fig. 2, taken from the study with Neyroz and republished in Psychologie des traumes (Psychology of the dreams) [17], shows the curve of sleep depth as measured using Griesbach's esthesiometer. During the study, the researchers subjected the participants to tactile-pressure stimuli during the night, which produced a single but continuous reaction, rather than a series of separate reactions. The researchers registered not only the stimulus pressure level at which the subject woke up, but also the pressure level that provoked the subject to move. As a result, the two authors considered the beginning of waking to be caused by the stimulus (incomplete awakening) and the complete awakening showing the conscious reaction to the stimulus, thus defining two deep sleep curves [16,17] (Fig. 2). Upon awakening, the subjects were asked if they had dreamt.

The solid line represents the curve of the conscious reaction (complete awakening), the dotted line represents the curve of unconscious reactions (incomplete awakening), and the dashed line represents the dream curve. The elevation of the curve shows the presence of the dream immediately after awakening. De Sanctis and Neyroz carried out these observations for six consecutive months, observing four normal and five abnormal subjects. De Sanctis in the description of the figure reproduced here (Fig. 2) explicitly noted that in the first half of the night (deep sleep), dreams are rare; on the other hand, in the second half of the night (light sleep), dreams increase [17].

As shown by the dashed lines (Fig. 2), the scholars were also a step away from understanding that dreams occur in specific phases of sleep. 


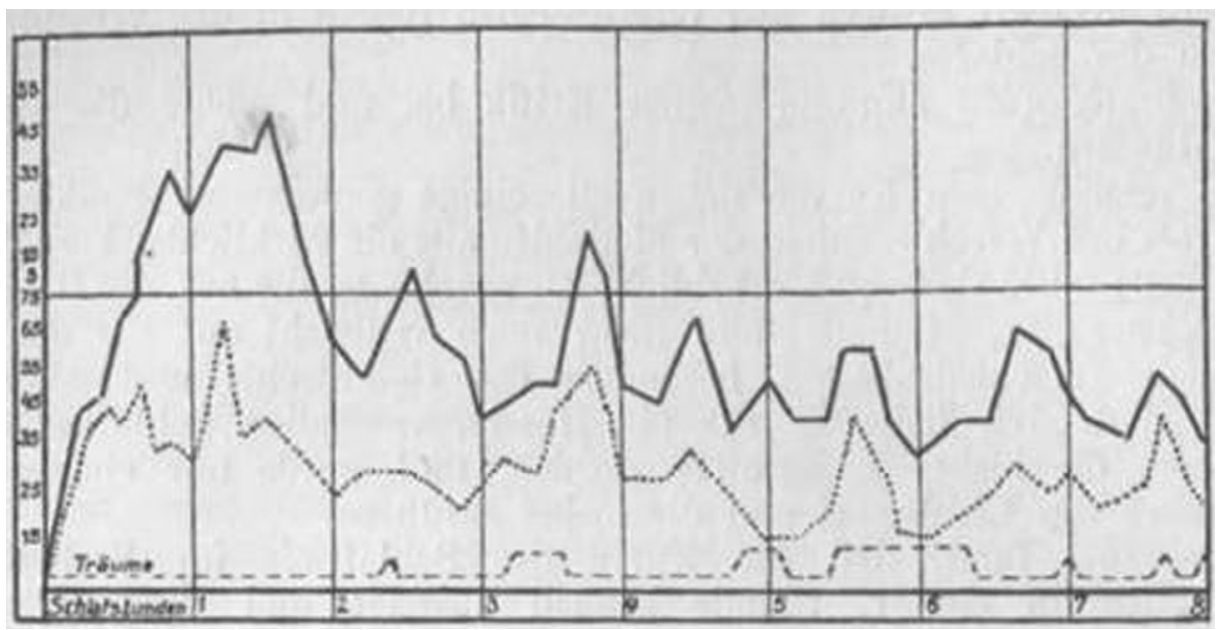

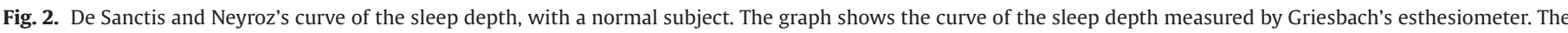

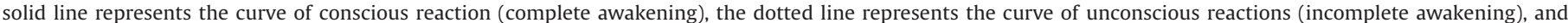

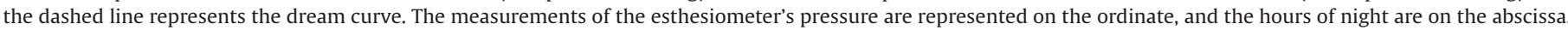

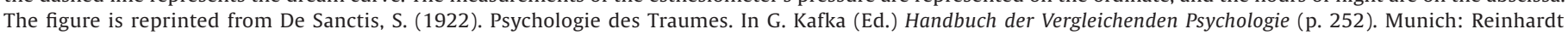
(copyright-free).

\subsection{Respiratory rhythm during sleep and dream}

Later, De Sanctis expanded the methodology of psychophysiological research on sleep and dreaming in particular through observations and the recording of respiration, using the Marey's pneumograph and Brondgeest's pansphygmograph [18-20]. These tools furnished a graphical representation of the time occupied in the various phases of respiration by obtaining a curve or pneumatogram of the respiratory movements [20].

In the 1920s, Antonio Mendicini (1890-1938), under the supervision of De Sanctis at the Laboratory of Experimental Psychology of Rome, used chest pneumography to analyze the respiratory rate of a normal woman. As described in an article published in the Archivio Generale di Neurologia e Psichiatria, Mendicini and De Sanctis also attempted to demonstrate that in many cases, this respiratory rate becomes wider and more frequent during periods of deep sleep [19]. The experiments brought to light the presence of breathing synchronization and desynchronization when sleeping.

The chest pneumogram results in Fig. 3 show a steady and uniform respiratory rhythm during deep sleep, with no alterations that were typical in the waking state. It also expresses a synchronization phase of the rhythm of the breath.

In the pneumogram in Fig. 4, we can see particular abnormalities in the respiratory rhythm, as well as a spontaneous awakening of the woman toward the end of the curve. This shows the existence of respiratory desynchronization at the exact point that the participant noted that she was dreaming. Through these experiments, the authors argued that, very often, respiratory abnormalities occurred in correspondence to dreams, waking the participants during periods of desynchronized breathing.

\subsection{Toward a psycho- and neurophysiological model of dreaming}

In Physiological conditions of the dream [12], De Sanctis repeated, once again, that the more intense the stimulus used to arouse the sleeper, the deeper the sleep. On the basis of his studies, he noted that "dreams vary with the depth of sleep" [12] and that "the behavior of the sleeper may show, to a trained eye, the presence of a dream, even during deep sleep and in cases where the person claims not to know whether he dreamed or not" [12]. By analyzing the evolution of the cerebral cortex, De Sanctis highlighted the presence of brain segments that corresponded to old formation in animals and newly formed structures characterizing human consciousness. The author traced the origin of dreams in old brain systems that are activated without the control of the consciousness: "We can sufficiently explain the phenomenon of the liberation of the subconscious by assessing the special physiology of the sleeper. At the inhibition of sensory and psych-motor processes, even if the inhibition is partial, the processes correspond with the genesis of other

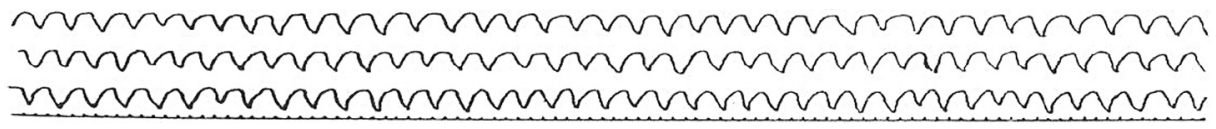

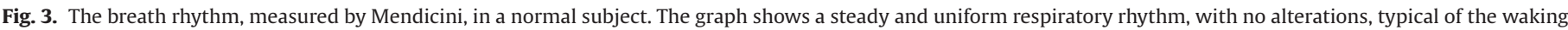

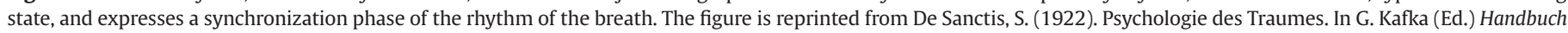
der Vergleichenden Psychologie (p. 235). Munich: Reinhardt (copyright-free).

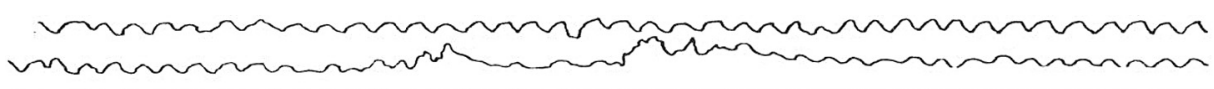

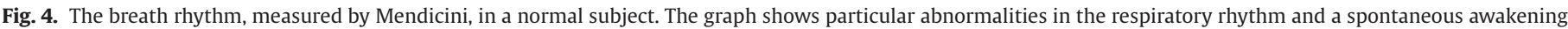

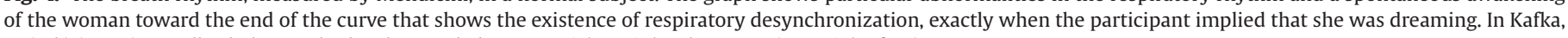
G. (Ed.) (1922). Handbuch der Vergleichenden Psychologie. Munich: Reinhardt, p. 236 (copyright-free). 
processes located in the cortex or in the subcortical segments of the brain" [12].

According to the Italian author, the attempts to localize the sleep and dream functions at the biological level had already been carried out by some of the period's scholars. In 1890, the Austrian physician, Ludwig Mauthner (1840-1894), discovered a hypnic center in the midbrain by comparing normal subjects and subjects with "sleeping sickness." Following the comparison, Mauthner asserted that during sleep, the centripetal and centrifugal transmission of stimuli would be interrupted [21]. In 1914, Hans Henning, a German psychologist and assistant at the Institut der Akademie zu Frankfurt, already pointed out the intimate link between dreams and sleep. Henning developed the physiological hypothesis of the shortcircuit, which would provide a reason for the oneiric symbolism. Henning argued that the stimulation of a single brain area would activate the surrounding areas. More specifically, he hypothesized that two brain areas would give rise to a short circuit that would be the physiologic basis for the associative phenomenon, as in the case of the dream [22]. Moreover, De Sanctis also took into account Albert Salmon's 1905 work, Sull'origine del sonno (On the origin of sleep), in which the author situated the sleep center in the subcortical area, located in the transition from the diencephalon to the midbrain [23].

Finally, if we extensively analyze De Sanctis' article, Nuovi contributi alla psicofisiologia dei sogni (New contributions to the psychophysiology of dreams), published in 1933 in the Rivista di Psicologia [14], as well as a shorter article, Psychophysiology of the dream, published in 1934 in Character and Personality [24], we can see how De Sanctis neurophysiologically connected dreaming to "ideas from the brain stem," that "the cortex belatedly and almost always inaccurately comments by the oneiric representations" [14], that occur at different stages of depth-of-sleep curve. Therefore, the elements of the dream, deriving from the earliest neurophysiological structures, are reworked from the most advanced and latest cerebral cortex. The cerebral cortex, in turn, has distinct psychological expressions: "oneiric consciousness," which represent the systematized subconscious during the "waking consciousness." The oneiric consciousness is associated with the early development of the nervous system, and depends on the brain stem, which is active with biological commitments from birth.
Hence, the systematic and critical analysis of his research and hypothetical assumptions about the central nervous system that were developed by scholars of different nationalities and from different disciplines led De Sanctis to build a theory about dreaming, taking into account a psycho- and neurophysiological standpoint. Thus, De Sanctis' novel ways of examining data are all the more surprising given the limited means available at his time.

\section{Conclusions}

De Sanctis' ideas appear to have been ahead of some of the key points made by today's modern research on the topic. To date, two models remain hegemonic in the study of dreams: the dichotomous model of rapid eye movement (REM) and non-REM sleep, and Hobson and McCarley's activation-synthesis theory (1977) recently updated in the AIM (activation-input-modulation) model, using a neuro-psychological point of view.

As seen in Fig. 2, De Sanctis explicitly described the two "curves of sleep" and a "curve of dream," noting that dreams occur in the second part of the night and during phases that show a desynchronization of the respiratory rhythm (Figs. 4 and 5) [17].

The conclusions arrived at by our author in some way seem to anticipate the current debate on the correspondence of the REM phase with oneiric activity that, after Aserinsky and Kleitman's [25] discovery, brought to light how dreaming may occur in the different phases of sleep [26-29]. Moreover De Sanctis explicitly states that dreams are the product of ideas triggered by the brain steam, and elaborated by the cortex (Fig. 5) [14].

As is well known, approximately 40 years afterwards in The brain as a dream state generator: An activation-synthesis hypothesis of the dream process [30], Hobson and McCarley proposed that during sleep the brain is activated periodically while sensory inputs and motor outputs are blocked, except for the oculomotor outputs. After being "activated" by random stimuli from the pontine areas, the brain compares these inputs with stored sensorimotor data and "synthesizes" the contents of the dream [31].

This work thus highlights the fact that De Sanctis should be recognized for attempting to localize brain functions and phases of the dream in a way that seems to anticipate the contemporary

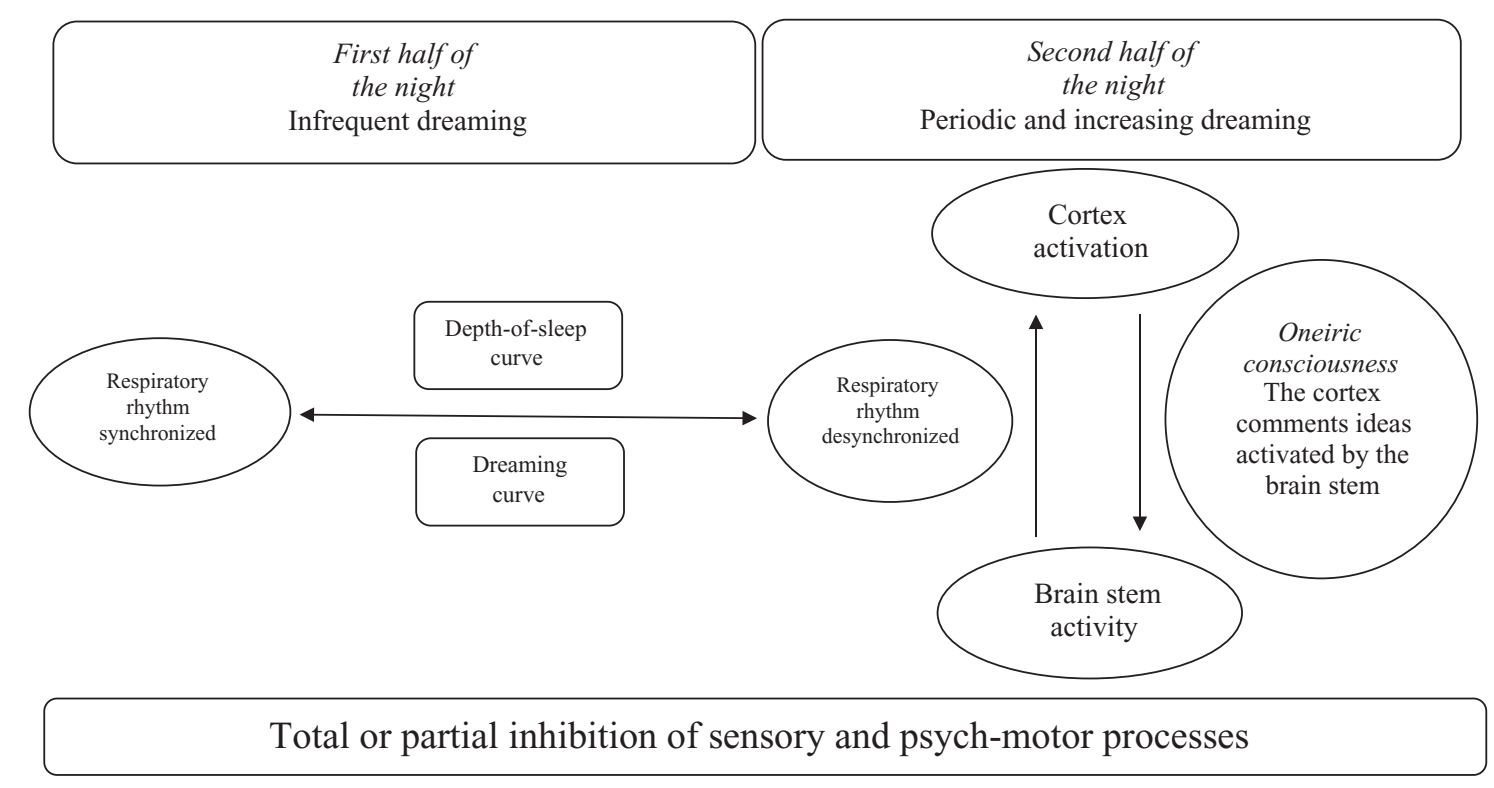

Fig. 5. De Sanctis' psycho- and neuro-physiological model of dreaming. 
research, although his attempts relied merely on the tools and knowledge of human anatomy available during his time [12,14,16,19].

As is well known, the importance of recording brain waves for systematic research was highlighted during WWII following progressive improvements to electronic equipment with the introduction of new electro-physiological technologies that gave rise to modern neurophysiology [32]. Moreover, in 1949 Moruzzi and Mogun discovered the controls of the Reticular Activating System through new electrophysiological recordings [33]. In the following years, the REMNREM sleep and the activation-synthesis models, which would soon became dominant in the scientific study of dreams, borrowed from insights into mental functioning that were previously expressed by the scholars of the early 20th century. Their research, based on psycho-physiological registrations, were, however, put aside following the use of the electro-physiological analysis methods for measuring brain activity that were systematically used in modern experimentation. In light of the arguments put forward, our historiographical assumption was that there was both a psychological and physiological view for the study of dreaming activities, even prior to Freud's ideas. These studies that were undervalued can be now reviewed in order to fully understand the elements of continuity and/or discontinuity with the past of contemporary neuroscientific research on dreaming.

\section{Conflict of interest}

The ICMJE Uniform Disclosure Form for Potential Conflicts of Interest associated with this article can be viewed by clicking on the following link: http://dx.doi.org/10.1016/j.sleep.2014.08.015.

\section{Acknowledgments}

This work was carried out by the Archive and Laboratory of History of Psychology at the Dynamic and Clinical Psychology Department at the Sapienza University of Rome. All authors, listed in alphabetical order, contributed equally to the creation of this work. We thank Professor Fabrizio Doricchi who gave us insights into De Sanctis' use of a scientific framework in dreaming research, in addition to generously suggesting a hypothesis of a correspondence between the psychophysiology of De Sanctis and contemporary research.

\section{References}

[1] Cimino G, Lombardo GP (editors) Sante De Sanctis tra psicologia generale e psicologia applicata. Milano: Franco Angeli, 2004.

[2] Pigman GW. The dark forest of authors: Freud and nineteenth-century dream theory. Psychoanal Hist 2002;4:141-65.
[3] Baldwin JM, editor. Dictionary of philosophical psychology. New York: Macmillan; 1911.

[4] Lavie P, Hobson JA. Origin of dreams: anticipation of modern theories in the philosophy and physiology of the eighteenth and nineteenth centuries. Psychol Bull 1986;100(2):229-40.

[5] Hobson JA. The dreaming brain. New York: Basic Books; 1988.

[6] Kroker K. The sleep of others and the transformations of sleep research. Toronto: Toronto University Press; 2007.

[7] Carroy J. Nuits savantes. Une histoire des reves (1800-1945). Paris: EHESS; 2012.

[8] Lombardo GP, Foschi R. Escape from the dark forest: the experimentalist standpoint of the Sante De Sanctis dreaming psychology. Hist Hum Sci 2008;21:45-69.

[9] Foschi R, Lombardo GP, editors. Sante De Sanctis. La psicologia del sogno. Torino: Antigone; 2006.

[10] Lombardo GP, Foschi R. Sante De Sanctis research on dreams and his relationships with German-speaking scholars. Physis 2010;47(1-2):133-46.

[11] Berger H. Ueber das Elektroenkephalogramm des Menschen. Arch Psychiatr Nervenkr 1929;87:527-70

[12] De Sanctis S. Le condizioni fisiologiche del sogno. Riv Biol 1920;2:474-507.

[13] De Sanctis S. I sogni: studi clinici e psicologici di un alienista. Torino: Fratelli Bocca; 1899.

[14] De Sanctis S. Nuovi contributi alla psicofisiologia del sogno. Riv Psicol 1933;29:12-32.

[15] Basner M. Arousal threshold determination in 1862: Kohlschütter's measurements on the firmness of sleep. Sleep Med 2010;11(4):417-22.

[16] De Sanctis S, Neyroz U. Experimental investigations concerning the depth of sleep. Psychol Rev 1902;9:254-82.

[17] De Sanctis S. Psychologie des traumes. In: Kafka G, editor. Handbuch der vergleichenden psychologie. Munich: Reinhardt; 1922. p. 233-329.

[18] Marey EJ. Etudes physiologiques sur les caractères graphiques des battements du coeur et des mouvements respiratoires. Paris: Baillière; 1865.

[19] Mendicini A. La respirazione nella melanconia durante il sonno. Archivio generale di Neurologia e Psichiatria 1920;1:194-228.

[20] Landois L A manual of human physiology, vol. 1. Philadelphia: Blakiston; 1885.

[21] Frankl-Hochwart L. K.k. Gesellschaft der aerzte zu Wien. Sitzung vom 23. u. 30. mai 1890. Neurol Centralbl 1890;9(14):445-7.

[22] Henning H. Der Traum: eir assoziativere kurzschluss. Wiesbaren: Bergnam; 1914.

[23] Salmon A. Sull'origine del sonno. Firenze: Niccolai; 1905.

[24] De Sanctis S. The psychophysiology of the dream. Charact Person 1933;2:26987.

[25] Aserinsky E, Kleitman N. Regular occurring periods of eye motility and concomitant phenomena, during sleep. Science 1953;118:273-4.

[26] Foulkes D. Dreaming: a cognitive-psychological approach. Hillsdale: Erlbaum; 1985.

[27] Domhoff GW. The scientific study of dreams: neural networks, cognitive development, and content analysis. Washington, DC: American Psychological Association; 2003.

[28] Solms M. Dreaming and REM sleep are controlled by different brain mechanisms. In: Pace-Schott E, Solms M, Blagrove M, Harnad S, editors. Sleep and dreaming: scientific advances and reconsiderations. Cambridge: Cambridge University Press; 2003. p. 51-8.

[29] McNamara P, Johnson P, McLaren D, Harris E, Beauharnais C, Auerbach S. Rem and NRem sleep mentation. Int Rev Neurobiol 2010;92:69-86.

[30] Hobson JA, McCarley R. The brain as a dream state generator: an activationsynthesis hypothesis of the dream process. Am J Psychiatry 1977;134:1335-48.

[31] Palagini L, Rosenlicht N. Sleep, dreaming, and mental health: a review of historical and neurobiological perspectives. Sleep Med Rev 2011;15(3):179-86.

[32] Zappoli R. Psicofisiologia. Cenni storici e prospettive attuali. Nuova Riv Neurol 1996;6(4):123-30.

[33] Moruzzi G, Magoun HW. Brain stem reticular formation and activation of the EEG. Electroencephalogr Clin Neurophysiol 1949;1(4):455-73. 